\title{
Chronic administration of AM251 improves albuminuria and renal tubular structure in obese rats
}

\author{
Kayte A Jenkin', Lannie O’Keefe', Anna C Simcocks', Esther Grinfeld', \\ Michael L Mathai, ${ }^{1,2}$, Andrew J McAinch' ${ }^{1}$ and Deanne H Hryciw ${ }^{3}$ \\ ${ }^{1}$ College of Health and Biomedicine, Centre for Chronic Disease Prevention and Management, \\ Victoria University, St Albans Campus, PO Box 14428, Melbourne, Victoria 8001, Australia \\ ${ }^{2}$ The Florey Institute of Neuroscience and Mental Health, Parkville, Melbourne, Victoria 3052, Australia \\ ${ }^{3}$ Department of Physiology, The University of Melbourne, Parkville, Melbourne, Victoria 3010, Australia
}

\author{
Correspondence \\ should be addressed \\ to D H Hryciw \\ Email \\ Deanne.Skelly@ \\ unimelb.edu.au
}

\begin{abstract}
Modulation of the endocannabinoid system as an anti-obesity therapeutic is well established; however, the direct effects of cannabinoid receptor $1\left(\mathrm{CB}_{1}\right)$ antagonism on renal function and structure in a model of diet-induced obesity (DIO) are unknown. The aim of this study was to characterise the renal effects of the $C_{1}$ antagonist $A M 251$ in a model of DIO. Male Sprague-Dawley rats were fed a low- or high-fat diet (HFD: 40\% digestible energy from lipids) for 10 weeks to elicit DIO $(n=9)$. In a different cohort, rats were fed a HFD for 15 weeks. After 9 weeks consuming a HFD, rats were injected daily for 6 weeks with $3 \mathrm{mg} / \mathrm{kg} \mathrm{AM} 251(n=9)$ or saline via i.p. injection ( $n=9)$. After 10 weeks consuming a HFD, $C B_{1}$ and megalin protein expression were significantly increased in the kidneys of obese rats. Antagonism of $C_{1}$ with AM251 significantly reduced weight gain, systolic blood pressure, plasma leptin, and reduced albuminuria and plasma creatinine levels in obese rats. Importantly, there was a significant reduction in tubular cross-section diameter in the obese rats treated with AM251. An improvement in albuminuria was likely due to the reduction in tubular size, reduced leptinaemia and maintenance of megalin expression levels. In obese rats, AM251 did not alter diastolic blood pressure, sodium excretion, creatinine clearance or expression of the fibrotic proteins VEGFA, TGFB1 and collagen IV in the kidney. This study demonstrates that treatment with $\mathrm{CB}_{1}$ antagonist $\mathrm{AM} 251$ improves renal outcomes in obese rats.
\end{abstract}

\section{Key Words}

- cannabinoids

- obesity

- leptin

- kidney

\section{Introduction}

The prevalence of obesity and the subsequent adverse effects of associated co-morbidities has risen significantly in recent years, placing a substantial financial and social burden on societies worldwide ( $\mathrm{Ng}$ et al. 2014). Furthermore, obesity is a strong, independent risk factor for the development and progression of chronic kidney disease (CKD), even when confounding variables such as hyperglycaemia, diabetes or hypertension are accounted for (Griffin et al. 2008). Thus, it is important to identify physiological targets, which may ameliorate the progression of obesity and the subsequent decline in renal function.

The endocannabinoid system has been characterised as an important endogenous lipid signalling system, which can mediate the development of obesity via the regulation of food intake and energy expenditure

Published by Bioscientifica Ltd 
(Di Marzo 2008). We have recently demonstrated that activation of the cannabinoid receptor $2\left(\mathrm{CB}_{2}\right)$ in dietinduced obese rats can lead to improved renal function (Jenkin et al. 2015a). In the past decade, the $\mathrm{CB}_{1}$ has received growing interest for its anti-obesity potential. A number of studies have demonstrated that $\mathrm{CB}_{1}$ antagonists and inverse agonists are an effective anti-obesity therapeutic (Van Gaal et al. 2005, Janiak et al. 2007, Rosenstock et al. 2008, Nam et al. 2012, Tam et al. 2012). However, characterisation of the physiological effects of $\mathrm{CB}_{1}$ antagonism in the periphery is limited outside of metabolically active tissues (Sink et al. 2008, Son et al. 2010, Merroun et al. 2013). Therefore, it is essential to determine whether antagonism of $\mathrm{CB}_{1}$ in the periphery alters disease progression in other tissues to ensure a full investigation of its potential as a therapeutic target.

$\mathrm{CB}_{1}$ antagonists have been shown to improve renal outcomes in a number of disease states including diabetes and obesity (Janiak et al. 2007, Lim et al. 2009, Mingorance et al. 2009). Overexpression of $\mathrm{CB}_{1}$ has been identified in glomerular renal cells of animal models with type 1 (Barutta et al. 2010) and type 2 (Nam et al. 2012) diabetic nephropathy. Specifically, increased $\mathrm{CB}_{1}$ expression has been demonstrated in models of nephropathy in human proximal tubular cells in vitro (Lim et al. 2010, Nam et al. 2012) and our group has previously established that proximal tubule cells exposed to pathophysiological levels of glucose and albumin also contribute to increased $\mathrm{CB}_{1}$ expression (Jenkin et al. 2015b). Furthermore, in animal models of diabetic nephropathy, $\mathrm{CB}_{1}$ antagonism ameliorates proteinuria, albuminuria and plasma creatinine, and improves creatinine clearance in diabetic animals (Janiak et al. 2007, Barutta et al. 2010, Nam et al. 2012). In contrast, transgenic mice that overexpress $\mathrm{CB}_{1}$ exhibit significant increases in proteinuria and kidney weight compared with WT mice (Hsu et al. 2014). Therefore, modulation of $\mathrm{CB}_{1}$ appears to be an effective mechanism for the reduction of the pathophysiological changes associated with nephropathy. $\mathrm{CB}_{1}$ antagonism is thought to elicit improvements via the preservation of glomerular podocyte cells and reduced tubule apoptosis (Janiak et al. 2007, Barutta et al. 2010, Lim et al. 2010).

Despite these studies in models of diabetic nephropathy, the only analysis of $\mathrm{CB}_{1}$ as a therapeutic in obesitylinked nephropathy has been performed in obese Zucker rats or $d b / d b$ mice (Janiak et al. 2007, Lim et al. 2009), which lack a functional leptin signalling pathway. There are limitations of using this specific animal model to study obesity, as recent research has demonstrated that leptin and $\mathrm{CB}_{1}$ are functionally linked (Tam et al. 2012). Leptin is a hormone produced primarily by adipose tissue and is principally cleared by the kidneys (Hama et al. 2004). Hyperleptinaemia is associated with obesity and the progression of renal fibrosis via increased collagen deposition and transforming growth factor beta 1 (TGFB1) secretion by renal glomerular cells (Briffa et al. 2014). Obesity-related kidney damage leads to increased levels of protein and albumin in the urine. This functional change has been linked to altered renal expression of megalin (Tam et al. 2012), a transmembrane protein which regulates both albumin and leptin absorption in the renal tubules (Hama et al. 2004, Birn \& Christensen 2006, Hryciw et al. 2012). Thus, it is essential to characterise $C_{1}$ as a therapeutic for obesity-linked nephropathy in a model that contains a functional leptin signalling pathway.

Our group has previously established that the $\mathrm{CB}_{1}$ antagonist, AM251, significantly reduces proximal tubule hypertrophy in cultured HK2 cells (Jenkin et al. 2010). Thus, in light of the current limitations of how $\mathrm{CB}_{1}$ and its role in obesity-related renal function have been examined using models lacking a functional leptin pathway, it is essential that we characterise the in vivo outcomes of modulation of $\mathrm{CB}_{1}$ in a model of diet-induced obesity (DIO). The main aim of this study was to investigate whether treatment with the $\mathrm{CB}_{1}$ antagonist AM251 reverses renal dysfunction associated with obesity-related CKD and to determine the specific cellular mechanism for the improved function in a model of DIO.

\section{Materials and methods}

\section{Animals}

All animal experimental procedures were approved by Howard Florey Animal Ethics Committee (AEC 11-036), which operates under the guidelines of the National Health and Medical Research Council of Australia. Seven-week-old male Sprague-Dawley rats $(\sim 350 \mathrm{~g})$ were individually housed (cage dimensions; width $27.5 \times$ length $41 \times$ height $25.5 \mathrm{~cm}$ ) in an environmentally controlled laboratory (ambient temperature $22-24^{\circ} \mathrm{C}$ ) and maintained under a $12 \mathrm{~h}$ light:12 h darkness cycle (0700-1900 h).

\section{DIO model}

Rats were randomly assigned to receive either a high-fat diet (HFD; containing 40\% digestible energy from lipids (Specialty Feeds, Glen Forrest, WA, Australia)), or a control diet (lean; 10\% digestible energy from lipids, Barastoc Ltd (Melbourne, VIC, Australia)) for a period of 10 weeks

Published by Bioscientifica Ltd 
( $n=9$ /group), as described previously (Jenkin et al. 2015a). Throughout the duration of the study, animals were allowed to access food and water ad libitum. At the end of 10 weeks, model rats were anaesthetised via i.p. injection with $100 \mathrm{mg} / \mathrm{kg}$ sodium pentabarbitone (Virbac, Milperra, NSW, Australia) and killed via cardiac puncture. Kidneys and surrounding peri-renal fat pads were then removed, weighed and stored at $-80^{\circ} \mathrm{C}$ for further analyses.

\section{Chronic AM251 treatment in DIO}

The rats receiving control or AM251 treatment were sustained on a HFD for a total of 15 weeks. Nine weeks of a HFD was sufficient to induce DIO, with rats exhibiting significant increases in body weight, body fat composition, hypertension and reduced renal function, as described previously by our group (Jenkin et al. 2015a). Thus, following 9 weeks of a HFD, rats were matched according to weight, body composition and blood pressure and were allocated to either obese control $(n=9)$ or $\mathrm{CB}_{1}$ antagonist AM251 groups $(n=9)$. For a further 6 weeks, rats were maintained on the HFD and treated daily with either vehicle control $(0.9 \%$ isotonic saline solution containing $0.75 \%$ Tween 80 ), or $3 \mathrm{mg} / \mathrm{kg}$ body weight of AM251 (Cayman Chemicals, Ann Arbour, MI, USA, dissolved in vehicle). AM251 has been shown previously in both animal models (Gatley et al. 1996, de Oliveira Alvares et al. 2006, Judge et al. 2009, Litvin et al. 2013) and in cell culture models (Lan et al. 1999, Deshpande et al. 2007) to act as a $\mathrm{CB}_{1}$ antagonist, with a high degree of selectivity (306-fold) for the $\mathrm{CB}_{1}$ receptor over $\mathrm{CB}_{2}$ (Lan et al. 1999). $\mathrm{CB}_{1}$ antagonism with AM251 treatment has also been demonstrated in transgenic animal models, where the effects with AM251 observed in WT mice are absent in $\mathrm{CB}_{1}$ knockout mice (Shearman et al. 2003, Haller et al. 2004). The concentration of $3 \mathrm{mg} / \mathrm{kg}$ for AM251 was based on previously published experimental studies using mice and rats (Barutta et al. 2010, Merroun et al. 2013). Treatments were administered via i.p. injection. Throughout the duration of the 15-week study, animals were allowed to access food and water ad libitum. Following the 15 weeks, rats were deeply anaesthetised with vaporised 3\% isoflurane (Abbott) and killed via cardiac puncture. Kidneys and surrounding peri-renal fat pads were then removed, weighed and stored at $-80^{\circ} \mathrm{C}$ for further analyses.

\section{Metabolic measurements}

Pre-treatment measurements were recorded at week 9, before the administration of control or AM251 treatments, and post-treatment measurements were recorded at week 15 in the final week of the intervention. Rat weight and food consumption were recorded daily throughout the experimental period. Pre-weighed food was provided to the rats to access ad libitum. After $24 \mathrm{~h}$, the amount of food remaining, including any on the bottom of the cages was recorded. Food consumption was calculated as the weight (g) of food provided subtracted by that recovered. Measurements for systolic and diastolic blood pressure were obtained from conscious rats using a non-invasive tail-cuff method with volume pressure recording software CODA 2 (Kent Scientific, Torrington, CT, USA; Daugherty et al. 2009). Glucose tolerance tests and insulin sensitivity tests were conducted as described previously (Jayasooriya et al. 2008, Xia et al. 2011) with minor modifications as glucose and insulin were administered via i.p. injection following an overnight and 2-h fast period respectively. Blood glucose in response to glucose $(2 \mathrm{~g} / \mathrm{kg})$ or insulin $(0.75 \mathrm{U} / \mathrm{kg})$ load was analysed as area under the curve (Le Floch et al. 1990).

\section{Plasma analysis}

Following cardiac puncture, blood was transferred into $10 \mathrm{ml}$ EDTA BD Vacutainer tubes (McFarlene Medical, Surrey Hills, NSW, Australia) and kept on ice until samples were centrifuged at $4000 \mathrm{~g}$ for $10 \mathrm{~min}$ at $4{ }^{\circ} \mathrm{C}$. The plasma layer was aspirated and stored at $-80^{\circ} \mathrm{C}$ for further analyses. Plasma levels of creatinine (Cayman Chemical Company, Ann Arbor, MI, USA), TGFB1 (Promega) and leptin (R\&D Systems, Minneapolis, MN, USA) were analysed according to the manufacturer's instructions.

\section{Renal function measurements}

Renal function was evaluated using $24 \mathrm{~h}$ urine samples collected using metabolic cages at weeks 9 and 15 of the obese control or AM251 treatment (pre- and post-treatment periods). Measurements of urinary albumin (ALPCO Diagnostics, Salem, NH, USA) and creatinine (Cayman Chemical Company) were determined using commercially available kits, according to the manufacturer's instructions. Lean age-matched rats $(n=6)$ were included in renal function measurements. Lean animals were fed a control diet for 16 weeks ad libitum (standard rodent chow; containing $10 \%$ digestible energy from lipids; sourced from Barastoc Ltd) (Jenkin et al. 2015a). Change in urinary albumin excretion ( $\Delta$ urinary albumin) was determined by post-treatment measurement subtracted from pretreatment measurement and was standardised for urinary creatinine. Urinary albumin was calculated as a ratio of $\mathrm{mg}$

Published by Bioscientifica Ltd. 
of albumin excreted divided by $\mathrm{mg}$ creatinine excreted (mg.dl/mg.dl Cr). Urinary sodium excretion was determined by analysing the sodium content in undiluted $24 \mathrm{~h}$ samples using the COBAS Integra 400 Plus System (Roche Diagnostics). Creatinine clearance $(\mathrm{ml} / \mathrm{min}$ per $\mathrm{kg}$ ) was calculated via the formula (urinary $\mathrm{vol}(\mathrm{ml} / \mathrm{min}) \times$ urinary creatinine concentration $(\mathrm{mg} / \mathrm{dl})) /($ plasma creatinine $(\mathrm{mg} / \mathrm{dl})$ ) and standardised for body weight (Keenan et al. 2000).

\section{Histological analysis}

Following post-mortem collection of the kidney, a crosssectional portion of the tissue was fresh frozen in optimal cutting temperature compound (Tissue-Tek, Torrance, CA, USA), and $5 \mu \mathrm{m}$ thick sections were cut using a HM 550 Cryostat (Thermo Fisher Scientific, Scoresby, VIC, Australia). Kidney sections were stained using haematoxylin and eosin and periodic acid schiff (PAS; Hughes \& Gobe 2007). Sections were imaged at $200 \times$ magnification (Carl Zeiss microscope) and at least 20 random glomeruli and 20 renal tubule sections from each rat $(n=5-6)$ were analysed. In order to analyse glomerular area, the outer edges of all glomerular tufts were traced on a captured image, and the encircled area was determined using the Image Analysis Software (Axiovision Rel. 4.8; Zeiss, Jena, Germany; Henegar et al. 2001). Tubular diameter was analysed at the widest point for cross-sectional diameter on captured bright-field images using the Axiovision 4.8 Image Analysis Software; the software is used to convert arbitrary pixels into microns $(\mu \mathrm{m})$ as detailed previously (Jonassen et al. 2008).

\section{Western blotting protocol}

Protein was isolated from individual rat kidneys as described previously (Slattery et al. 2011, Jenkin et al. 2013, 2015a). Aliquots (40-100 $\mu \mathrm{g}$ ) of protein lysates were separated on a 7.5-20\% SDS-PAGE gel and transferred onto a nitrocellulose membrane. $\mathrm{CB}_{1}$ (Cayman Chemicals), megalin (Santa Cruz Biotechnology), TGFB1 (Abcam, Cambridge, UK), collagen IV (Abcam) and vascular endothelial growth factor (VEGFA; Abcam) were detected using western blot analysis from kidney lysate using specific antibodies, with $\beta$-actin (Sigma-Aldrich) as a loading control. Secondary antibodies, anti-mouse and anti-rabbit were purchased from Sigma-Aldrich. Band densitometry was analysed using the Image Lab Software (Bio-Rad Laboratories). When reporting protein content, data were calculated by the volume intensity of the protein divided by the volume intensity of $\beta$-actin loading control, with protein content expressed in arbitrary units.

\section{Statistical analysis}

The SPSS statistical package software (SPSS, Inc.) was used for all statistical analysis. All data are presented as mean \pm s.E.M. Differences between lean and obese rats or AM251- and saline control-treated obese rats were analysed using independent samples $t$-test for two group direct analyses of measurements for obese control and AM251 groups. In measurements that were taken at both pre- and post-treatment time points, data were analysed using a repeated-measures ANOVA. Significance was considered when $P<0.05$.

\section{Results}

\section{Renal $\mathrm{CB}_{1}$ and megalin expression in DIO rats}

In whole kidney extract, $\mathrm{CB}_{1}$ protein was significantly increased in DIO rats fed a HFD for a period of 10 weeks compared with lean standard chow-fed rats (Fig. 1, $n=9$, $P<0.05$ ). Megalin protein expression was also significantly increased in DIO rats fed a HFD for 10 weeks, compared with lean standard chow-fed rats (Fig. $1, n=8, P<0.05$ ). No differences between lean and HFD-fed DIO rats were detected for $\beta$-actin, which was used as a loading control.

\section{Metabolic parameters in control and AM251-treated obese rats}

We have recently shown that this model of DIO leads to significant increases in weight, adiposity, diastolic and systolic blood pressure compared with lean animals fed a standard chow diet and that this model does not lead to alterations in glucose tolerance or insulin sensitivity (Jenkin et al. 2015a). Herein, we have shown that treatment with $\mathrm{CB}_{1}$ antagonist AM251, in DIO rats, induced improvements in percentage weight gain, systolic blood pressure and hyperleptinaemia compared with obese controls. Obese control and obese rats treated with AM251 were at similar weights pre-treatment, but obese rats treated with AM251 were significantly lighter at the conclusion of the treatment period compared with control obese rats (Table $1, n=9, P<0.05$ ). This was due to significantly reduced weight gain (main effect $P<0.05$, interaction $P<0.05$, Fig. 2) across the 6-week treatment period, compared with obese control rats. AM251 treatment in obese rats led to a transient reduction in

Published by Bioscientifica Ltd. 
A
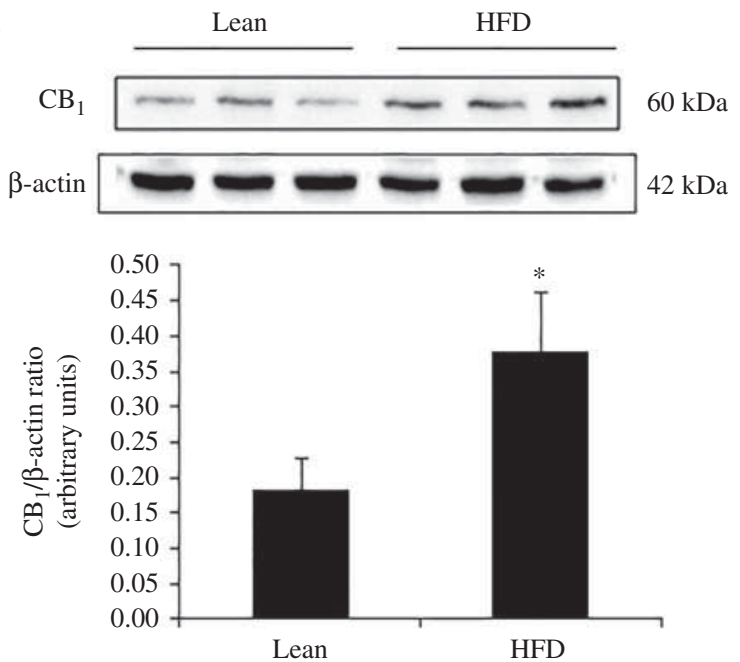

B
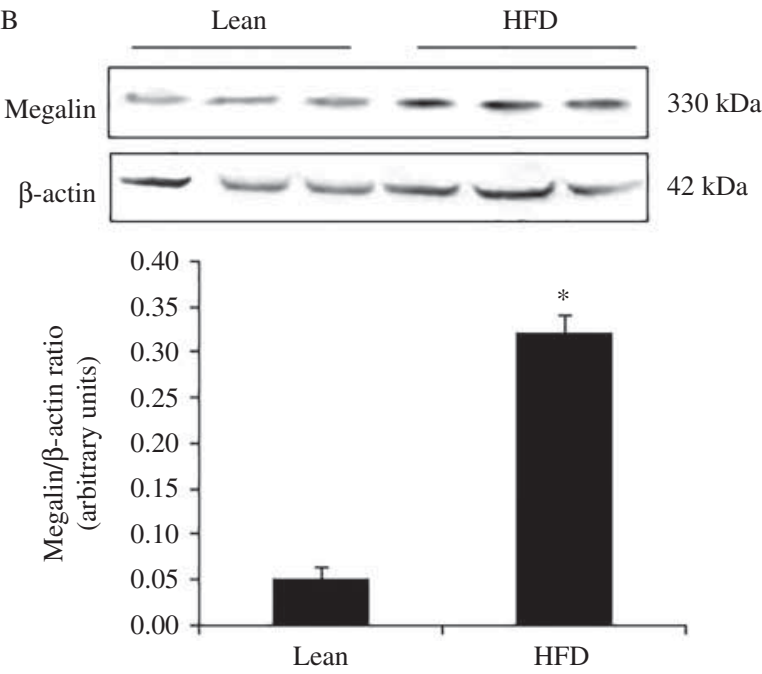

\section{Figure 1}

$\mathrm{CB}_{1}$ protein expression in whole kidney lysate of rats fed a standard chow (lean) or high-fat diet (HFD). (A) Representative western blot and quantification of $\mathrm{CB}_{1}$ expression in kidney lysate from rats at 10 weeks. (B) Representative western blot and quantification of megalin expression in kidney lysate from rats at 10 weeks. Significance is indicated by

* compared with lean standard chow-fed rats $(P<0.05, n=8-9)$.

food consumption for the first 2 weeks of treatment (Fig. 2, $n=9, P<0.05$ ). AM251-treated obese rats exhibited significantly reduced systolic blood pressure (Table 1 , $n=9$, main effect $P=0.382$, interaction $P<0.05$ ) and significant reductions in plasma leptin concentrations, compared with obese control rats (Fig. 2, $n=9, P<0.05$ ). Glucose tolerance, insulin sensitivity and diastolic blood pressure were not significantly altered by AM251 treatment compared with obese control rats (Fig. 3). All metabolic measurements are outlined in Table 1.

\section{Effect of AM251 treatment on renal morphology in $D I O$ rats}

In obese rats, AM251 treatment did not have any significant effects on gross kidney weight, kidney weight standardised for body weight or gross peri-renal fat weight area compared with obese controls or lean age-matched animals (Table 1). Glomerular cross-sectional area was not altered by treatment with AM251 (Fig. 4). However, obese rats treated with AM251 did exhibit significant reductions in peri-renal fat pad weight standardised for body weight compared with obese controls (Table $1, n=9, P<0.05$ ). Although this measure was reduced in obese AM251-treated animals, lean age-matched rats exhibited significantly lower amounts of peri-renal fat standardized for body weight (Table 1, $n=6-9$, $P<0.05)$. Histological analysis with PAS staining showed that tubular cross-sectional diameter was significantly smaller in obese AM251-treated rats compared with obese control (Fig. 4, $n=5-6, P<0.05$ ), indicating that AM251 treatment may reverse tubular hypertrophic morphological changes associated with obesity-related renal damage. Furthermore, obese control rats were shown to have significantly higher tubular cross-sectional diameter than age-matched lean rats (Table $1, n=5-6, P<0.05$ ). However, no significant differences were found between the AM251treated animals (Table 1) and age-matched lean controls, indicating that AM251 may indeed reduce obesity-related tubular hypertrophy.

\section{Functional renal outcomes in control and AM251-treated obese rats}

In obese rats, treatment with AM251 significantly improved renal outcomes as measured by albuminuria and plasma creatinine. Change in urinary albumin excretion was significantly reduced in obese rats treated with AM251 compared with obese controls (Fig. 5A, $n=9$, $P<0.05)$. Lean age-matched animals were included to illustrate functional renal outcomes compared with obese rats treated with AM251 and no significant differences in urinary protein, urinary albumin excretion or plasma creatinine were determined (Fig. 5, $n=6-9, P<0.05$ ). Plasma creatinine, which was measured at the posttreatment time point only, was significantly lower in AM251-treated rats post-treatment compared with obese control (Fig. 5, $n=9, P<0.05$ ). No significant differences or interactions were found between lean or obese control rats compared with obese animals treated with AM251 for urinary sodium excretion or estimated creatinine clearance (Fig. 5, $n=6-9$ ).

Published by Bioscientifica Ltd. 
Table 1 Analysis of metabolic and renal histological measures of lean, DIO Sprague-Dawley rats (obese control) and DIO SpragueDawley rats treated with $\mathrm{CB}_{1}$ antagonist, $\mathrm{AM} 251$

\begin{tabular}{l}
\hline Measure \\
Body weight (g) \\
Food consumption (g/day) \\
Diastolic blood pressure (mmHg) \\
Systolic blood pressure (mmHg) \\
Glucose tolerance (AUC) \\
Insulin sensitivity (AUC) \\
Plasma TGFB1 (ng/ml) \\
Plasma leptin (ng/ml) \\
Kidney weight (g) \\
Kidney weight/body weight (\%) \\
Peri-renal fat weight (g) \\
Peri-renal weight/body weight (\%) \\
Tubular cross-sectional \\
diameter ( $\mu \mathrm{m})$
\end{tabular}

\begin{tabular}{|c|c|}
\hline \multicolumn{2}{|c|}{ Lean } \\
\hline Pre treatment & Post treatment \\
\hline $539.6 \pm 11.83$ & $597.8 \pm 17.28$ \\
\hline $32.1 \pm 1.59$ & $31.1 \pm 1.60$ \\
\hline $85 \pm 6.47$ & $89 \pm 5.76$ \\
\hline $121 \pm 6.49$ & $123 \pm 7.82$ \\
\hline $338.4 \pm 93.15$ & $537.0 \pm 38.88$ \\
\hline $184.3 \pm 66.22$ & $158.25 \pm 53.35$ \\
\hline- & $13.9 \pm 0.92$ \\
\hline - & $8.79 \pm 0.94$ \\
\hline - & $1.72 \pm 0.09$ \\
\hline - & $0.29 \pm 0.01$ \\
\hline- & $5.52 \pm 0.60$ \\
\hline - & $0.91 \pm 0.09$ \\
\hline- & $10.17 \pm 0.23$ \\
\hline
\end{tabular}

\begin{tabular}{cc}
\multicolumn{2}{c}{ Obese control } \\
\cline { 1 - 1 } Pre treatment & Post treatment \\
\cline { 1 - 1 } $582.9 \pm 14.35$ & $655.9 \pm 19.23$ \\
$23.7 \pm 0.95$ & $21.7 \pm 0.51$ \\
$100 \pm 5.56$ & $105 \pm 5.83$ \\
$137 \pm 6.23$ & $144 \pm 7.07$ \\
$590.8 \pm 81.54$ & $560.4 \pm 82.92$ \\
$219.7 \pm 36.81$ & $245.6 \pm 43.82$ \\
- & $18.4 \pm 3.26$ \\
- & $22.6 \pm 5.07$ \\
- & $1.66 \pm 0.05$ \\
- & $0.25 \pm 0.01$ \\
& $11.46 \pm 0.09$ \\
- & $1.93 \pm 0.16$ \\
- & $12.74 \pm 0.19$ \\
&
\end{tabular}

\begin{tabular}{|c|c|}
\hline \multicolumn{2}{|c|}{ AM251 } \\
\hline Pre treatment & Post treatment \\
\hline $\begin{array}{c}576.0 \pm 11.51 \\
22.5 \pm 0.61 \\
105 \pm 3.38 \\
151 \pm 4.89 \\
485.3 \pm 39.86 \\
176.7 \pm 28.04 \\
- \\
- \\
- \\
-\end{array}$ & $\begin{array}{c}607.2 \pm 12.43^{\mathrm{a}, \mathrm{b}} \\
19.3 \pm 0.53 \\
91 \pm 5.59 \\
135 \pm 7.43^{\mathrm{a}, \mathrm{b}} \\
594.8 \pm 43.51 \\
172.2 \pm 29.03 \\
15.8 \pm 1.71 \\
9.28 \pm 2.10^{\mathrm{a}} \\
1.68 \pm 0.05 \\
0.27 \pm 0.01 \\
8.50 \pm 1.19 \\
1.25 \pm 0.21^{\mathrm{a}} \\
10.76 \pm 0.26^{\mathrm{a}}\end{array}$ \\
\hline
\end{tabular}

a Significance is indicated between diet-induced obese rats treated with AM251 and obese control at the same time point (pre- or post-treatment, $P<0.05$, $n=9$ ).

Interaction was observed between group and time period (two-way repeated measures ANOVA, $P<0.05, n=9$ ). Data are shown as average \pm S.E.M.

\section{Renal expression of megalin and fibrotic markers in AM251-treated obese rats}

Recently, our group has shown that this model of DIO in Sprague-Dawley rats does not alter the renal expression of a number of fibrotic markers including collagen IV, TGFB1, fibronectin and $\alpha$-smooth muscle actin; however, VEGFA is significantly reduced in DIO rats fed a HFD for 10 weeks (Jenkin et al. 2015a). For the first time, herein we have shown that in obese rats, plasma concentrations of TGFB1 were not altered by treatment with AM251 compared with obese controls (Table 1). Western blot analysis of megalin, collagen IV, TGFB1 and VEGFA demonstrated that treatment with AM251 in obese rats did not significantly alter levels of these proteins in whole kidney tissue of obese rats (Fig. 6, n=9). No differences between obese control and AM251-treated rats were detected for $\beta$-actin, which was used as a loading control.

\section{Discussion}

In this study, expression of $\mathrm{CB}_{1}$ was significantly increased in the kidneys of DIO rats. Treatment with the $\mathrm{CB}_{1}$ antagonist, AM251, reduced weight gain and significantly reduced systolic blood pressure, plasma leptin, albuminuria and plasma creatinine levels in obese rats. Furthermore, tubular cross-sectional diameter was reduced in obese rats treated with AM251. The tubular cross-sectional diameter of AM251-treated animals was comparable to the measurements of lean age-matched rats. Significantly, the renal expression of the scavenger receptor megalin was up-regulated in obese rats fed a HFD for 10 weeks, but was not altered by treatment with AM251. Collectively, these data indicate that the $\mathrm{CB}_{1}$ antagonist, AM251, may improve renal outcomes in a model of DIO.

It has been well documented that overweight or obese individuals have an increased risk of developing CKD (Wang et al. 2008, Afkarian et al. 2013). We have previously demonstrated that male Sprague-Dawley rats fed a HFD for 10 weeks exhibit an obese phenotype, with increased body weight, adiposity and blood pressure (Jenkin et al. 2015a). Furthermore, this model of DIO has been shown to reduce renal function, as measured by increased proteinuria, albuminuria and urinary creatinine excretion (Jenkin et al. 2015a). Herein, we have shown for the first time that after 10 weeks in a rat model of DIO, expression of $\mathrm{CB}_{1}$ in kidney tissue of obese rats is significantly increased compared with lean rats. Furthermore, we have shown that in our model of DIO, treatment with AM251 was able to significantly reduce weight gain, systolic blood pressure and hyperleptinaemia, which is supported by previous research (Janiak et al. 2007, Mingorance et al. 2009, Nam et al. 2012, Tam et al. 2012).

Importantly, AM251 treatment in obese rats improved a number of markers of obesity-related renal damage. This included a reduction in total urinary albumin excretion and plasma creatinine levels compared with obese control rats. These findings are similar to previous studies, which demonstrated, in models of diabetic nephropathy when

Published by Bioscientifica Ltd 


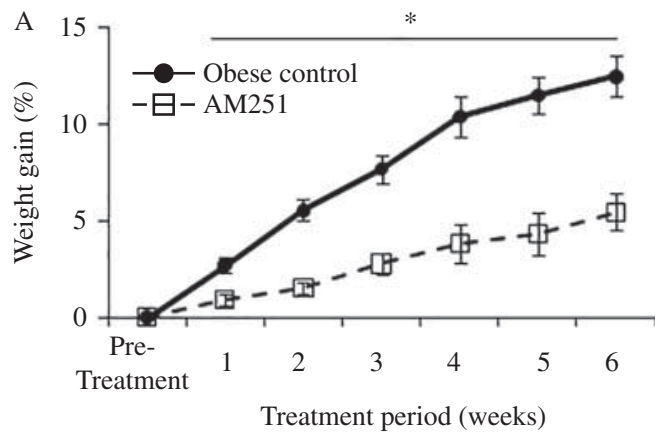

B
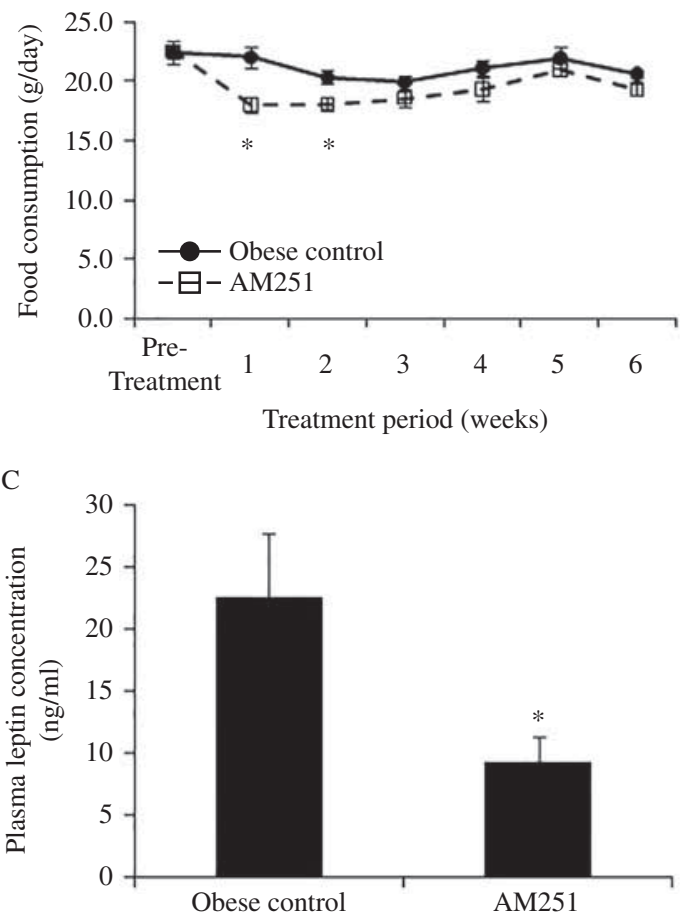

Figure 2

Metabolic outcomes of kidneys of AM251 in obese rats. (A) Obese AM251treated rats exhibited significantly reduced weight gain (\% of pretreatment weight) from weeks 1 to 6 of treatment compared with obese controls. (B) Food consumption (g/day) of obese control and AM251 obese rats. (C) Plasma leptin concentration in obese control and AM251 obese rats. Significance is indicated by * compared with obese controls $(P<0.05, n=9)$.

targeting $\mathrm{CB}_{1}$ with an antagonist or inverse agonist, rodents exhibit improved renal function (Janiak et al. 2007, Barutta et al. 2010, Jenkin et al. 2012, Nam et al. 2012). In this study, we have added to this knowledge by demonstrating that $\mathrm{CB}_{1}$ antagonism with AM251 improves albuminuria in a DIO model. We have found that AM251 treatment in obese rats was able to significantly reduce hyperleptinaemia induced by obesity, similar to a previous study (Tam et al. 2012). Our findings are further supported by a recent study, which employed a transgenic mouse model to overexpress $\mathrm{CB}_{1}$ and was shown that animals exhibited higher levels of proteinuria without alterations in blood glucose compared with the WT group (Hsu et al. 2014).

Prior to this study, the investigation of modulation of $\mathrm{CB}_{1}$ as a therapeutic target in obesity-related renal dysfunction has only been studied in obese Zucker rats (Janiak et al. 2007). In these rats, antagonism of $\mathrm{CB}_{1}$ resulted in improvements in proteinuria and creatinine clearance through the reduction in renal hypertrophy and fibrosis (Janiak et al. 2007). However, obese Zucker rats have alterations in their leptin signalling pathway. As leptin signalling and $\mathrm{CB}_{1}$ function are linked (Tam et al. 2012), the outcomes of the study by Janiak et al. (2007) needed further investigation. To add to this, our data have demonstrated that, in obese rats, the scavenger receptor megalin was significantly up-regulated, while treatment with AM251 in DIO rats did not significantly alter levels of renal megalin expression compared with obese control. Renal expression of megalin in obese humans has yet to be characterised; however, our group has shown that, in vitro, renal proximal tubule cells acutely exposed to leptin decreases megalin expression and albumin uptake in proximal tubule cells (Briffa et al. 2014). However, the increase in megalin expression in our obese model contradicts our in vitro findings and the research of Tam et al. (Tam et al. 2012, Briffa et al. 2014), who demonstrated a reduction in megalin expression in obese mice which also exhibited reduced glucose tolerance and insulin sensitivity, which was reversed when mice were treated with a $\mathrm{CB}_{1}$ inverse agonist. In our model of DIO, no differences in response to either glucose or insulin were detected between AM251-treated rats and control rats. As megalin is down-regulated in isolated proximal tubule cells exposed to elevated glucose (Ishibashi 2004), and in the tubules of streptozotocin-induced diabetic SpragueDawley rats (Russo et al. 2007), we can suggest that the reduction in megalin in the kidney in the Tam model may be due to the exposure of elevated circulating glucose. The lack of change of megalin in the AM251-treated obese rats, which also exhibited reduced tubular hypertrophy, may have allowed a higher capacity for the binding of megalin to albumin in the filtrate, leading to the improved reabsorption and reduced urinary albumin excretion compared with obese control rats. Previous research in diabetic nephropathy has attributed improved renal function primarily to glomerular changes, with reduced loss of nephrin and podocin, observed in AM251-treated animals (Barutta et al. 2010, Hsu et al. 2014). Albumin is

Published by Bioscientifica Ltd. 

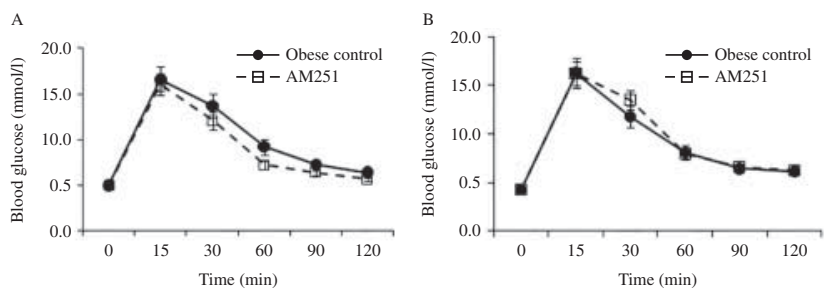

Figure 3

Response to glucose and insulin in obese rats treated with AM251 compared with obese control. (A) Glucose tolerance test pre-treatment.

filtered by the glomerulus and largely reabsorbed by proximal tubule cells, and damage to either of these structures can result in albuminuria (Birn \& Christensen 2006). Although we did not measure podocin or nephrin protein levels, no significant changes in glomerular histology or size was observed between obese control and AM251-treated rats, suggesting that the tubules are the main site of action of $\mathrm{CB}_{1}$ action in obesity prior to the onset of hyperglycaemia.

The lack of hyperglycaemia in our model of DIO is indicative of early pathophysiological changes associated with obesity (Kahn et al. 2006). It has been well documented that obesity is associated with CKD, even in the absence of confounding factors including elevated fasting glucose and overt diabetes and high blood pressure (Kramer et al. 2005, Griffin et al. 2008, Mathew et al. 2011). Currently, we have two hypotheses for the renal damage in our model of DIO in the absence of hyperglycaemia. First, the elevated levels of megalin observed in this study are likely to initially increase albumin uptake. We and others have shown that exposure to elevated albumin increases fibrotic damage in proximal tubules (Wohlfarth et al. 2003, Slattery et al. 2013). This leads to an elevation in fibrotic proteins, which in turn down-regulates albumin endocytosis that ultimately leads to renal dysfunction
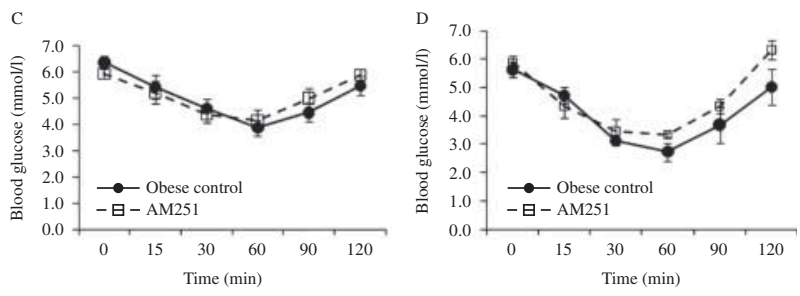

(B) Glucose tolerance test post-treatment. (C) Insulin sensitivity test pre-treatment. (D) Insulin sensitivity test post-treatment.

(Gekle et al. 2003). Secondly, leptin has been well characterised to be elevated in humans and animal models of obesity (Ahima \& Flier 2000, Banks et al. 2004, Briffa et al. 2013). Current work by our group has demonstrated that elevated leptin exposure alters the metabolic function of tubular cells (Briffa et al. 2014), which may account for the renal dysfunction observed in our model.

In addition to targeting the renal system, AM251 significantly reduced systolic blood pressure of DIO rats compared with obese controls. Systolic blood pressure specifically has been demonstrated to be a strong predictor of renal disease in humans and in rats (Gonzalez-Albarran et al. 2003). The role of $\mathrm{CB}_{1}$ in the cardiovascular system is complex; the influence of the receptor on haemodynamics depends on the experimental context, species of animal and, in clinical trials, patient background, including age, race and sex (Pacher et al. 2005). It has been hypothesised that AM251 treatment may be affecting systolic blood pressure via either sympathetic nervous system activity or activation of the renin-angiotensin-aldosterone system, as both systems are implicated in changes to cardiovascular haemodynamics (Dobrian et al. 2000). Despite this, reductions in both weight and systolic blood pressure may also contribute to the improvements in albuminuria in this model of DIO.
A

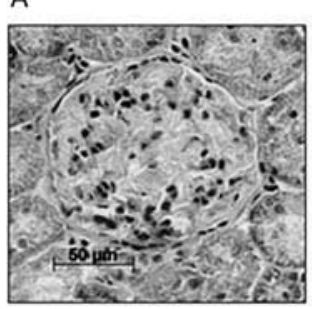

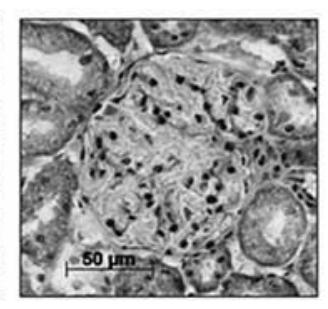

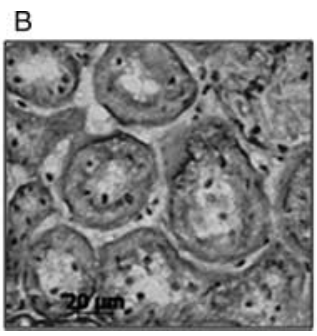

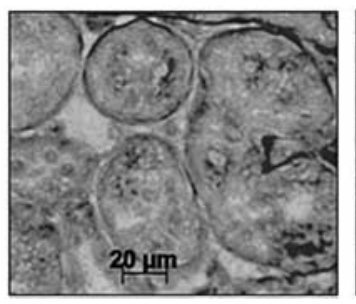

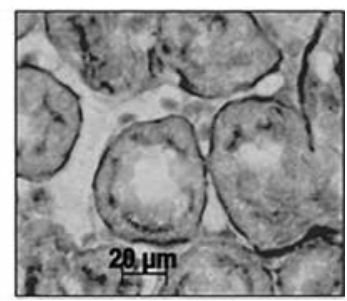

Figure 4

Morphological analysis of kidneys of AM251-treated obese rats. Representative pictures of using $200 \times$ magnification. (A) Haematoxylin and eosin (H\&E) staining of the glomerulus of obese control $(n=5)$ and obese rats treated with AM251 ( $n=5)$. (B) Periodic acid schiff (PAS) staining of the renal tubules of lean age-matched rats $(n=6)$, obese control rats $(n=5)$ and obese rats treated with $\operatorname{AM} 251(n=6)$.

Published by Bioscientifica Ltd. 


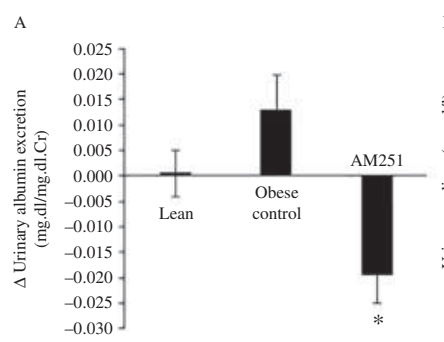

B

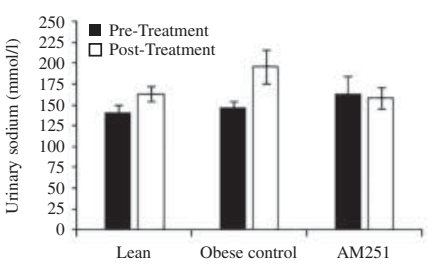

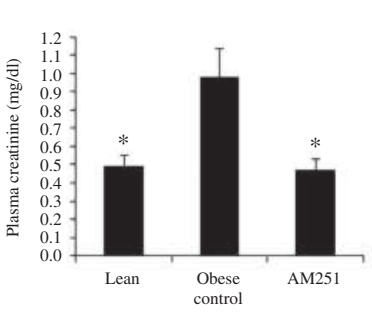

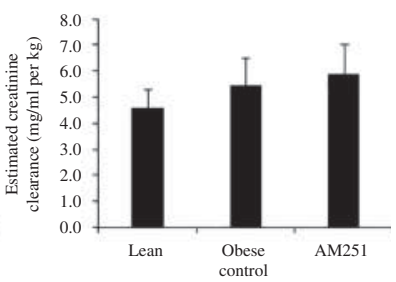

Figure 5

Functional renal outcomes of lean age-matched rats and obese rats treated with AM251 compared with obese control. (A) Change $(\Delta)$ urinary albumin excretion. (B) Urinary sodium excretion. (C) Plasma creatinine

Hyperleptinaemia is positively correlated with the degree of obesity (Ahima \& Flier 2000, Tam et al. 2012) and is also associated with increased TGFB1 production and collagen deposition leading to increased fibrosis in CKD (Wolf \& Ziyadeh 1999, Briffa et al. 2013). Previous studies have established that fibrotic markers including TGFB1, collagen IV and VEGFA are up-regulated in the kidney in obesity-related nephropathy (Jiang et al. 2005, Cignarelli \& Lamacchia 2007, Mathew et al. 2011, Briffa et al. 2013, Nolan et al. 2013, Zhang et al. 2013). Indeed, it has been shown that in lean transgenic mice that overexpress $\mathrm{CB}_{1}$, there is an increase in glomerular expression of VEGFA (Hsu et al. 2014). However, we have demonstrated that, in AM251-treated obese rats, there is no significant alteration in renal expression of collagen IV, TGFB1 or VEGFA. Therefore, alternative targets are likely to be involved in the improvement of renal dysfunction observed in our model of DIO. In support of this proposal, treatment with $\mathrm{CB}_{1}$ antagonist, AM251, in cultured proximal tubule cells exposed to hyperlipidaemic conditions reduced apoptosis via signalling pathways that activate endoplasmic reticulum stress (Lim et al. 2010). Therefore, $\mathrm{CB}_{1}$ may modulate endoplasmic reticulum function to improve the renal outcomes in obesity. Thus, further investigation is required to determine which downstream targets $\mathrm{CB}_{1}$ may be mediating in a DIO model of nephropathy.

AM251 treatment in obese rats significantly reduced plasma creatinine levels, compared with obese controls. Creatinine is a by-product of skeletal muscle and is primarily removed from the blood via glomerular filtration (Toffaletti \& McDonnell 2008). Interestingly, although we observed a significant reduction in plasma creatinine of obese rats treated with AM251, no differences were found between groups for estimated creatinine clearance standardised to body weight. This potentially could be due to the significant reduction in body weight observed in obese animals treated with AM251 compared with obese controls. Lower levels of concentration. (D) Estimated creatinine clearance. Significance difference is indicated by * compared with obese controls $(P<0.05, n=6-9)$.

plasma creatinine are likely the effect of overall reduced skeletal muscle mass (reflected in lower body weight), which produces creatinine, as indicated by lower plasma creatinine observed in both AM251-treated obese and lean agematched rats compared with obese controls. As no significant differences were found in creatinine clearance between either the lean or obese control compared with obese AM251-treated rats, it is possible that the renal filtration of creatinine is not affected to the same extent as
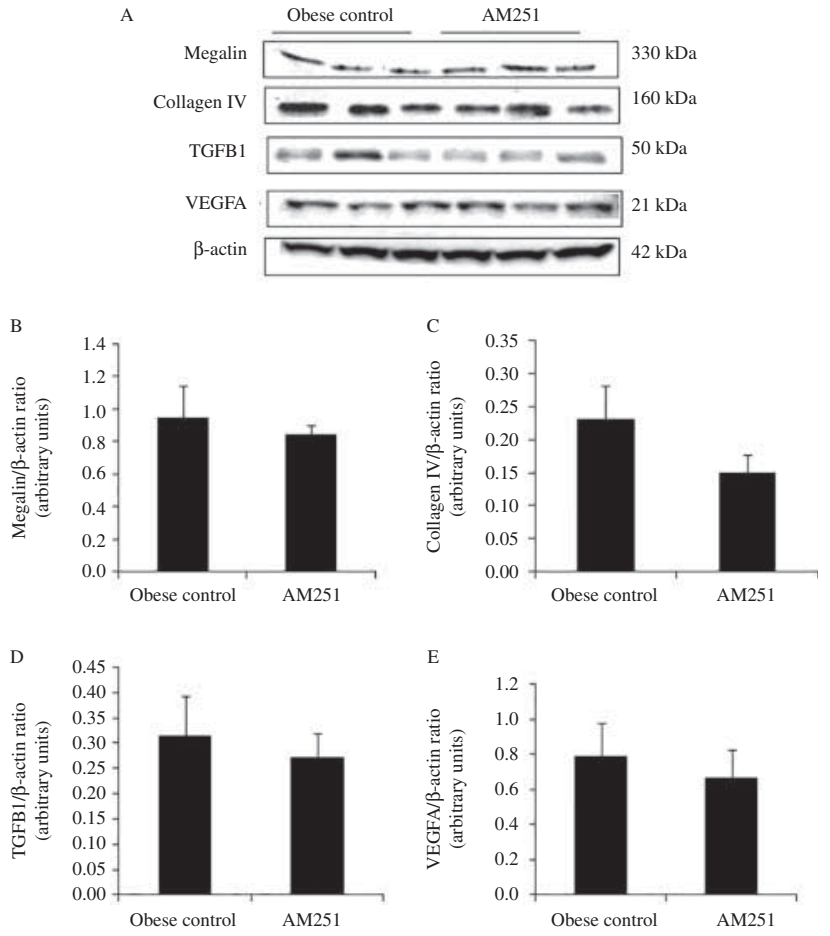

Figure 6

Protein expression of kidney lysate from diet-induced obese rats treated with AM251 compared with obese controls $(n=8-9)$. (A) Representative western blots of obese control and AM251-treated rats. (B) Quantification of megalin protein in kidney lysate. (C) Quantification of collagen IV protein in kidney lysate. (D) Quantification of TGFB1 protein in kidney lysate. (E) Quantification of VEGFA protein in kidney lysate.

Published by Bioscientifica Ltd. 
the tubular handling of urinary albumin in obese rats. Furthermore, while previously published work has demonstrated that specificity of $\mathrm{AM} 251$ for the $\mathrm{CB}_{1}$ receptor is high (Lan et al. 1999), and the use of $\mathrm{CB}_{1}$ knockout models have demonstrated that AM251 acts to block the effects of $\mathrm{CB}_{1}$ (Shearman et al. 2003, Haller et al. 2004), our study has not evaluated whether complete $\mathrm{CB}_{1}$ antagonism was achieved in our model of DIO. Compounded with this, AM251, along with other established $\mathrm{CB}_{1}$ antagonists may also be acting via other CB receptors, particularly GPR55 (Ryberg et al. 2007, Kapur et al. 2009, Henstridge et al. 2010). However, these findings have been disputed by others. While we cannot rule out any interaction of the agonistic effect of GPR55 following AM251 treatment in DIO rats, it must be reiterated that the dosage utilised was similar to that reported in previously published studies, which have demonstrated $\mathrm{CB}_{1}$ antagonism using knockout models (Shearman et al. 2003, Haller et al. 2004).

In summary, this study has demonstrated that treatment with the $\mathrm{CB}_{1}$ antagonist, $\mathrm{AM} 251$, improves markers of renal damage, and specifically, that $\mathrm{CB}_{1}$ and megalin protein expression is significantly up-regulated in kidney lysate of rats fed a HFD. Furthermore, AM251 reverses hyperleptinaemia, maintains the increased renal expression of megalin and improves albuminuria and plasma creatinine. We propose that the mechanism for the improvement in albuminuria is via the maintenance of renal megalin levels and reduction in tubular size compared with obese controls. Furthermore, metabolic improvements, including reductions in surrounding peri-renal fat tissue, body weight, weight gain, food consumption and blood pressure, which have been characterised extensively elsewhere (Despres et al. 2005, Janiak et al. 2007, Rosenstock et al. 2008, Tam et al. 2012), were also observed in our model in response to AM251 treatment. This study identifies a potential role of $\mathrm{CB}_{1}$ modulation with the antagonist AM251 for the treatment of early obesity-related renal damage. Further investigation is required to identify which signalling pathways the $\mathrm{CB}_{1}$ receptor may be acting on to fully elucidate the role of $\mathrm{CB}_{1}$ within the renal system under obese conditions.

\section{Declaration of interest}

The authors declare that there is no conflict of interest that could be perceived as prejudicing the impartiality of the research reported.

\section{Funding}

This work was supported by the Allen Foundation ( $\mathrm{D} \mathrm{H} \mathrm{H}$ and A J M), and through the Australian Government's Collaborative Research Networks (CRN) programme (A J M). Scholarship funding was provided by the
Australian Postgraduate Award ( $\mathrm{K} \mathrm{A} J$ and $\mathrm{L} \mathrm{O}$ ) and Australian Rotary Health (A C S).

\section{References}

Afkarian M, Sachs MC, Kestenbaum B, Hirsch IB, Tuttle KR, Himmelfarb J \& de Boer IH 2013 Kidney disease and increased mortality risk in type 2 diabetes. Journal of the American Society of Nephrology 24 302-308. (doi:10.1681/ASN.2012070718)

Ahima RS \& Flier JS 2000 Adipose tissue as an endocrine organ. Trends in Endocrinology and Metabolism 11 327-332. (doi:10.1016/S10432760(00)00301-5)

Banks WA, Coon AB, Robinson SM, Moinuddin A, Shultz JM, Nakaoke R \& Morley JE 2004 Triglycerides induce leptin resistance at the blood-brain barrier. Diabetes 53 1253-1260. (doi:10.2337/diabetes.53.5.1253)

Barutta F, Corbelli A, Mastrocola R, Gambino R, Di Marzo V, Pinach S, Rastaldi MP, Perin PC \& Gruden G 2010 Cannabinoid receptor 1 blockade ameliorates albuminuria in experimental diabetic nephropathy. Diabetes 59 1046-1054. (doi:10.2337/db09-1336)

Birn H \& Christensen EI 2006 Renal albumin absorption in physiology and pathology. Kidney International 69 440-449. (doi:10.1038/sj.ki.5000141)

Briffa JF, McAinch AJ, Poronnik P \& Hryciw DH 2013 Adipokines as a link between obesity and chronic kidney disease. American Journal of Physiology. Renal Physiology 305 F1629-F1636. (doi:10.1152/ajprenal. 00263.2013)

Briffa JF, Grinfeld E, Mathai ML, Poronnik P, McAinch AJ \& Hryciw DH 2014 Acute leptin exposure reduces megalin expression and upregulates TGF $\beta 1$ in cultured renal proximal tubule cells. Molecular and Cellular Endocrinology 401 25-34. (doi:10.1016/j.mce.2014.11.024)

Cignarelli M \& Lamacchia O 2007 Obesity and kidney disease. Nutrition, Metabolism, and Cardiovascular Diseases 17 757-762. (doi:10.1016/ j.numecd.2007.03.003)

Daugherty A, Rateri D, Hong L \& Balakrishnan A 2009 Measuring blood pressure in mice using volume pressure recording, a tail-cuff method. Journal of Visualized Experiments 27 1-2. (doi:10.3791/1291)

Deshpande LS, Blair RE, Ziobro JM, Sombati S, Martin BR \& DeLorenzo RJ 2007 Endocannabinoids block status epilepticus in cultured hippocampal neurons. European Journal of Pharmacology 558 52-59. (doi:10.1016/j.ejphar.2006.11.030)

Despres JP, Golay A \& Sjostrom L 2005 Effects of rimonabant on metabolic risk factors in overweight patients with dyslipidemia. New England Journal of Medicine 353 2121-2134. (doi:10.1056/NEJMoa044537)

Di Marzo V 2008 The endocannabinoid system in obesity and type 2 diabetes. Diabetologia 51 1356-1367. (doi:10.1007/s00125-008-1048-2)

Dobrian AD, Davies MJ, Prewitt RL \& Lauterio TJ 2000 Development of hypertension in a rat model of diet-induced obesity. Hypertension $\mathbf{3 5}$ 1009-1015. (doi:10.1161/01.HYP.35.4.1009)

Gatley SJ, Gifford AN, Volkow ND, Lan R \& Makriyannis A $1996{ }^{123}$ I-labeled AM251: a radioiodinated ligand which binds in vivo to mouse brain cannabinoid $\mathrm{CB}_{1}$ receptors. European Journal of Pharmacology $\mathbf{3 0 7}$ 331-338. (doi:10.1016/0014-2999(96)00279-8)

Gekle M, Knaus P, Nielsen R, Mildenberger S, Freudinger R, Wohlfarth V, Sauvant C \& Christensen EI 2003 Transforming growth factor- $\beta 1$ reduces megalin- and cubilin-mediated endocytosis of albumin in proximal-tubule-derived opossum kidney cells. Journal of Physiology 552 471-481. (doi:10.1113/jphysiol.2003.048074)

Gonzalez-Albarran O, Gomez O, Ruiz E, Vieitez P \& Garcia-Robles R 2003 Role of systolic blood pressure on the progression of kidney damage in an experimental model of type 2 diabetes mellitus, obesity, and hypertension (Zucker rats). American Journal of Hypertension 16 979-985. (doi:10.1016/S0895-7061(03)01000-8)

Griffin KA, Kramer H \& Bidani AK 2008 Adverse renal consequences of obesity. American Journal of Physiology. Renal Physiology 294 F685-F696. (doi:10.1152/ajprenal.00324.2007) 
Haller J, Varga B, Ledent C \& Freund TF $2004 \mathrm{CB}_{1}$ cannabinoid receptors mediate anxiolytic effects: convergent genetic and pharmacological evidence with $\mathrm{CB}_{1}$-specific agents. Behavioural Pharmacology 15 299-304. (doi:10.1097/01.fbp.0000135704.56422.40)

Hama H, Saito A, Takeda T, Tanuma A, Xie Y, Sato K, Kazama JJ \& Gejyo F 2004 Evidence indicating that renal tubular metabolism of leptin is mediated by megalin but not by the leptin receptors. Endocrinology 145 3935-3940. (doi:10.1210/en.2004-0074)

Henegar JR, Bigler SA, Henegar LK, Tyagi SC \& Hall JE 2001 Functional and structural changes in the kidney in the early stages of obesity. Journal of the American Society of Nephrology 12 1211-1217.

Henstridge CM, Balenga NA, Schroder R, Kargl JK, Platzer W, Martini L, Arthur S, Penman J, Whistler JL, Kostenis E et al. 2010 GPR55 ligands promote receptor coupling to multiple signalling pathways. British Journal of Pharmacology 160 604-614. (doi:10.1111/j.1476-5381.2009. 00625.x)

Hryciw DH, Jenkin KA, Simcocks AC, Grinfeld E, McAinch AJ \& Poronnik P 2012 The interaction between megalin and ClC-5 is scaffolded by the $\mathrm{Na}^{(+)}-\mathrm{H}^{(+)}$exchanger regulatory factor 2 (NHERF2) in proximal tubule cells. International Journal of Biochemistry \& Cell Biology $\mathbf{4 4} 815-823$. (doi:10.1016/j.biocel.2012.02.007)

Hsu YC, Lei CC, Shih YH, Ho C \& Lin CL 2014 Induction of proteinuria by cannabinoid receptors 1 signaling activation in $\mathrm{CB}_{1}$ transgenic mice. American Journal of the Medical Sciences 349 162-168. (doi:10.1097/MAJ. 0000000000000352)

Hughes J \& Gobe G 2007 Identification and quantification of apoptosis in the kidney using morphology, biochemical and molecular markers. Nephrology 12 452-458. (doi:10.1111/j.1440-1797.2007.00854.x)

Ishibashi F 2004 High glucose reduces albumin uptake in cultured proximal tubular cells (LLC-PK1). Diabetes Research and Clinical Practice 65 217-225. (doi:10.1016/j.diabres.2004.02.003)

Janiak P, Poirier B, Bidouard JP, Cadrouvele C, Pierre F, Gouraud L, Barbosa I, Dedio J, Maffrand JP, Le Fur G et al. 2007 Blockade of cannabinoid $\mathrm{CB}_{1}$ receptors improves renal function, metabolic profile, and increased survival of obese Zucker rats. Kidney International 72 1345-1357. (doi:10.1038/sj.ki.5002540)

Jayasooriya AP, Mathai ML, Walker LL, Begg DP, Denton DA, CameronSmith D, Egan GF, McKinley MJ, Rodger PD, Sinclair AJ et al. 2008 Mice lacking angiotensin-converting enzyme have increased energy expenditure, with reduced fat mass and improved glucose clearance. PNAS 105 6531-6536. (doi:10.1073/pnas.0802690105)

Jenkin KA, McAinch AJ, Grinfeld E \& Hryciw DH 2010 Role for cannabinoid receptors in human proximal tubular hypertrophy. Cellular Physiology and Biochemistry 26 879-886. (doi:10.1159/000323997)

Jenkin KA, Verty AN, McAinch AJ \& Hryciw DH 2012 Endocannabinoids and the renal proximal tubule: an emerging role in diabetic nephropathy. International Journal of Biochemistry \& Cell Biology $\mathbf{4 4}$ 2028-2031. (doi:10.1016/j.biocel.2012.07.008)

Jenkin KA, McAinch AJ, Briffa JF, Zhang Y, Kelly DJ, Pollock CA, Poronnik P \& Hryciw DH 2013 Cannabinoid receptor 2 expression in human proximal tubule cells is regulated by albumin independent of ERK1/2 signaling. Cellular Physiology and Biochemistry 32 1309-1319. (doi:10.1159/000354529)

Jenkin KA, O'Keefe L, Simcocks AC, Briffa JF, Mathai ML, McAinch AJ \& Hryciw DH 2015a Renal effects of chronic pharmacological manipulation of $\mathrm{CB}_{2}$ in rats with diet induced obesity. British Journal of Pharmacology [in press]. (doi:10.1111/bph.13056)

Jenkin KA, McAinch AJ, Zhang Y, Kelly DJ \& Hryciw DH 2015b Elevated $\mathrm{CB}_{1}$ and GPR55 receptor expression in proximal tubule cells and whole kidney exposed to diabetic conditions. Clinical and Experimental Pharmacology \& Physiology 42 256-262. (doi:10.1111/1440-1681.12355)

Jiang T, Wang Z, Proctor G, Moskowitz S, Liebman SE, Rogers T, Lucia MS, Li J \& Levi M 2005 Diet-induced obesity in C57BL/6J mice causes increased renal lipid accumulation and glomerulosclerosis via a sterol regulatory element-binding protein-1c-dependent pathway. Journal of Biological Chemistry 280 32317-32325. (doi:10.1074/jbc.M500801200)
Jonassen JA, San Agustin J, Follit JA \& Pazour GJ 2008 Deletion of IFT20 in the mouse kidney causes misorientation of the mitotic spindle and cystic kidney disease. Journal of Cell Biology 183 377-384. (doi:10.1083/ jcb.200808137)

Judge MK, Zhang Y \& Scarpace PJ 2009 Responses to the cannabinoid receptor-1 antagonist, AM251, are more robust with age and with high-fat feeding. Journal of Endocrinology 203 281-290. (doi:10.1677/ JOE-09-0210)

Kahn SE, Hull RL \& Utzschneider KM 2006 Mechanisms linking obesity to insulin resistance and type 2 diabetes. Nature $\mathbf{4 4 4} 840-846$. (doi:10.1038/nature05482)

Kapur A, Zhao P, Sharir H, Bai Y, Caron MG, Barak LS \& Abood ME 2009 Atypical responsiveness of the orphan receptor GPR55 to cannabinoid ligands. Journal of Biological Chemistry 284 29817-29827. (doi:10.1074/ jbc.M109.050187)

Keenan KP, Coleman JB, McCoy CL, Hoe CM, Soper KA \& Laroque P 2000 Chronic nephropathy in ad libitum overfed Sprague-Dawley rats and its early attenuation by increasing degrees of dietary (caloric) restriction to control growth. Toxicologic Pathology 28 788-798. (doi:10.1177/ 019262330002800604)

Kramer H, Luke A, Bidani A, Cao G, Cooper R \& McGee D 2005 Obesity and prevalent and incident CKD: the Hypertension Detection and Follow-Up Program. American Journal of Kidney Diseases 46 587-594. (doi:10.1053/j.ajkd.2005.06.007)

Lan R, Liu Q, Fan P, Lin S, Fernando SR, McCallion D, Pertwee R \& Makriyannis A 1999 Structure-activity relationships of pyrazole derivatives as cannabinoid receptor antagonists. Journal of Medicinal Chemistry 42 769-776. (doi:10.1021/jm980363y)

Le Floch JP, Escuyer P, Baudin E, Baudon D \& Perlemuter L 1990 Blood glucose area under the curve. Methodological aspects. Diabetes Care $\mathbf{1 3}$ 172-175. (doi:10.2337/diacare.13.2.172)

Lim AK, Ma FY, Nikolic-Paterson DJ, Thomas MC, Hurst LA \& Tesch GH 2009 Antibody blockade of c-fms suppresses the progression of inflammation and injury in early diabetic nephropathy in obese $d b / d b$ mice. Diabetologia 52 1669-1679. (doi:10.1007/s00125-009-1399-3)

Lim JC, Lim SK, Han HJ \& Park SH 2010 Cannabinoid receptor 1 mediates palmitic acid-induced apoptosis via endoplasmic reticulum stress in human renal proximal tubular cells. Journal of Cellular Physiology 225 654-663. (doi:10.1002/jcp.22255)

Litvin Y, Phan A, Hill MN, Pfaff DW \& McEwen BS $2013 \mathrm{CB}_{1}$ receptor signaling regulates social anxiety and memory. Genes, Brain, and Behavior 12 479-489. (doi:10.1111/gbb.12045)

Mathew AV, Okada S \& Sharma K 2011 Obesity related kidney disease. Current Diabetes Reviews 7 41-49. (doi:10.2174/157339911794273928)

Merroun I, Sanchez-Gonzalez C, Martinez R, Lopez-Chaves C, Porres JM, Aranda P, Llopis J, Galisteo M, Zarzuelo A, Errami M et al. 2013 Novel effects of the cannabinoid inverse agonist AM 251 on parameters related to metabolic syndrome in obese Zucker rats. Metabolism: Clinical and Experimental 62 1641-1650. (doi:10.1016/j.metabol. 2013.06.011)

Mingorance C, Alvarez de Sotomayor M, Jimenez-Palacios FJ, Callejon Mochon M, Casto C, Marhuenda E \& Herrera MD 2009 Effects of chronic treatment with the $\mathrm{CB}_{1}$ antagonist, rimonabant on the blood pressure, and vascular reactivity of obese Zucker rats. Obesity 17 1340-1347. (doi:10.1038/oby.2009.20)

Nam DH, Lee MH, Kim JE, Song HK, Kang YS, Lee JE, Kim HW, Cha JJ, Hyun YY, Kim SH et al. 2012 Blockade of cannabinoid receptor 1 improves insulin resistance, lipid metabolism, and diabetic nephropathy in $d b / d b$ mice. Endocrinology 153 1387-1396. (doi:10.1210/en.2011-1423)

Ng M, Fleming T, Robinson M, Thomson B, Graetz N, Margono C, Mullany EC, Biryukov S, Abbafati C, Abera SF et al. 2014 Global, regional, and national prevalence of overweight and obesity in children and adults during 1980-2013: a systematic analysis for the Global Burden of Disease Study 2013. Lancet 384 766-781. (doi:10.1016/ S0140-6736(14)60460-8) 
Nolan E, O'Meara YM \& Godson C 2013 Lipid mediators of inflammation in obesity-related glomerulopathy. Nephrology, Dialysis, Transplantation 28 iv22-iv29. (doi:10.1093/ndt/gft392)

de Oliveira Alvares L, Genro BP, Vaz Breda R, Pedroso MF, Da Costa JC \& Quillfeldt JA 2006 AM251, a selective antagonist of the $\mathrm{CB}_{1}$ receptor, inhibits the induction of long-term potentiation and induces retrograde amnesia in rats. Brain Research 1075 60-67. (doi:10.1016/ j.brainres.2005.11.101)

Pacher P, Batkai S \& Kunos G 2005 Blood pressure regulation by endocannabinoids and their receptors. Neuropharmacology $\mathbf{4 8}$ 1130-1138. (doi:10.1016/j.neuropharm.2004.12.005)

Rosenstock J, Hollander P, Chevalier S \& Iranmanesh A 2008 SERENADE: the Study Evaluating Rimonabant Efficacy in Drug-naive Diabetic Patients: effects of monotherapy with rimonabant, the first selective $\mathrm{CB}_{1}$ receptor antagonist, on glycemic control, body weight, and lipid profile in drug-naive type 2 diabetes. Diabetes Care 31 2169-2176. (doi:10.2337/dc08-0386)

Russo LM, del Re E, Brown D \& Lin HY 2007 Evidence for a role of transforming growth factor (TGF)- $\beta 1$ in the induction of postglomerular albuminuria in diabetic nephropathy: amelioration by soluble TGF- $\beta$ type II receptor. Diabetes 56 380-388. (doi:10.2337/db06-1018)

Ryberg E, Larsson N, Sjogren S, Hjorth S, Hermansson NO, Leonova J, Elebring T, Nilsson K, Drmota T \& Greasley PJ 2007 The orphan receptor GPR55 is a novel cannabinoid receptor. British Journal of Pharmacology 152 1092-1101. (doi:10.1038/sj.bjp.0707460)

Shearman LP, Rosko KM, Fleischer R, Wang J, Xu S, Tong XS \& Rocha BA 2003 Antidepressant-like and anorectic effects of the cannabinoid $\mathrm{CB}_{1}$ receptor inverse agonist AM251 in mice. Behavioural Pharmacology 14 573-582. (doi:10.1097/00008877-200312000-00001)

Sink KS, McLaughlin PJ, Wood JA, Brown C, Fan P, Vemuri VK, Peng Y, Olszewska T, Thakur GA, Makriyannis A etal. 2008 The novel cannabinoid $\mathrm{CB}_{1}$ receptor neutral antagonist AM4113 suppresses food intake and food-reinforced behavior but does not induce signs of nausea in rats. Neuropsychopharmacology 33 946-955. (doi:10.1038/sj.npp.1301476)

Slattery C, Jenkin KA, Lee A, Simcocks AC, McAinch AJ, Poronnik P \& Hryciw DH $2011 \mathrm{Na}^{+}-\mathrm{H}^{+}$exchanger regulatory factor 1 (NHERF1) PDZ scaffold binds an internal binding site in the scavenger receptor megalin. Cellular Physiology and Biochemistry 27 171-178. (doi:10.1159/ 000325219)

Slattery C, Jang Y, Kruger WA, Hryciw DH, Lee A \& Poronnik P 2013 $\gamma$-Secretase inhibition promotes fibrotic effects of albumin in proximal tubular epithelial cells. British Journal of Pharmacology 169 1239-1251. (doi:10.1111/bph.12214)

Son MH, Kim HD, Chae YN, Kim MK, Shin CY, Ahn GJ, Choi SH, Yang EK, Park KJ, Chae HW et al. 2010 Peripherally acting $\mathrm{CB}_{1}$-receptor antagonist: the relative importance of central and peripheral $\mathrm{CB}_{1}$ receptors in adiposity control. International Journal of Obesity $\mathbf{3 4}$ 547-556. (doi:10.1038/ijo.2009.253)

Tam J, Cinar R, Liu J, Godlewski G, Wesley D, Jourdan T, Szanda G, Mukhopadhyay B, Chedester L, Liow JS et al. 2012 Peripheral cannabinoid-1 receptor inverse agonism reduces obesity by reversing leptin resistance. Cell Metabolism 16 167-179. (doi:10.1016/j.cmet. 2012.07.002)

Toffaletti JG \& McDonnell EH 2008 Variation of serum creatinine, cystatin $\mathrm{C}$, and creatinine clearance tests in persons with normal renal function. Clinica Chimica Acta 395 115-119. (doi:10.1016/j.cca. 2008.05.020)

Van Gaal LF, Rissanen AM, Scheen AJ, Ziegler O \& Rossner S 2005 Effects of the cannabinoid-1 receptor blocker rimonabant on weight reduction and cardiovascular risk factors in overweight patients: 1-year experience from the RIO-Europe study. Lancet 365 1389-1397. (doi:10.1016/ S0140-6736(05)66374-X)

Wang Y, Chen X, Song Y, Caballero B \& Cheskin LJ 2008 Association between obesity and kidney disease: a systematic review and metaanalysis. Kidney International 73 19-33. (doi:10.1038/sj.ki.5002586)

Wohlfarth V, Drumm K, Mildenberger S, Freudinger R \& Gekle M 2003 Protein uptake disturbs collagen homeostasis in proximal tubulederived cells. Kidney International. Supplement 63 S103-S109. (doi:10.1046/j.1523-1755.63.s84.13.x)

Wolf G \& Ziyadeh FN 1999 Molecular mechanisms of diabetic renal hypertrophy. Kidney International 56 393-405. (doi:10.1046/j.15231755.1999.00590.x)

Xia X, Yan J, Shen Y, Tang K, Yin J, Zhang Y, Yang D, Liang H, Ye J \& Weng J 2011 Berberine improves glucose metabolism in diabetic rats by inhibition of hepatic gluconeogenesis. PLOS ONE 6 e16556. (doi:10.1371/journal.pone.0016556)

Zhang X, Li ZL, Woollard JR, Eirin A, Ebrahimi B, Crane JA, Zhu XY, Pawar AS, Krier JD, Jordan KL et al. 2013 Obesity-metabolic derangement preserves hemodynamics but promotes intrarenal adiposity and macrophage infiltration in swine renovascular disease. American Journal of Physiology. Renal Physiology 305 F265-F276. (doi:10.1152/ajprenal.00043.2013)

Received in final form 6 March 2015

Accepted 23 March 2015

Accepted Preprint published online 23 March 2015
(C) 2015 Society for Endocrinology Printed in Great Britain 